\title{
Vitamin D deficiency and whole-body and femur bone mass relative to weight in healthy newborns
}

\author{
Hope Weiler, Shirley Fitzpatrick-Wong, Rebecca Veitch, Heather Kovacs, Jeannine Schellenberg, \\ Ursula McCloy, Chui Kin Yuen
}

ß See related article page 769

\section{Abstract}

Background: Vitamin D is required for normal bone growth and mineralization. We sought to determine whether vitamin D deficiency at birth is associated with bone mineral content (BMC) of Canadian infants.

Methods: We measured plasma 25-hydroxyvitamin D [25(OH)D] as an indicator of vitamin D status in 50 healthy mothers and their newborn term infants. In the infants, anthropometry and lumbar, femur and whole-body BMC were measured within 15 days of delivery. Mothers completed a 24-hour recall and 3 -day food and supplement record. We categorized the vitamin D status of mothers and infants as deficient or adequate and then compared infant bone mass in these groups using nonpaired $t$ tests. Maternal and infant variables known to be related to bone mass were tested for their relation to BMC using backward stepwise regression analysis.

Results: Twenty-three (46\%) of the mothers and $18(36 \%)$ of the infants had a plasma $25(\mathrm{OH}) \mathrm{D}$ concentration consistent with deficiency. Infants who were vitamin D deficient were larger at birth and follow-up. Absolute lumbar spine, femur and whole-body BMC were not different between infants with adequate vitamin D and those who were deficient, despite larger body size in the latter group. In the regression analysis, higher whole-body BMC was associated with greater gestational age and weight at birth as well as higher infant plasma 25(OH)D.

Conclusion: A high rate of vitamin D deficiency was observed among women and their newborn infants. Among infants, vitamin D deficiency was associated with greater weight and length but lower bone mass relative to body weight. Whether a return to normal vitamin D status, achieved through supplements or fortified infant formula, can reset the trajectory for acquisition of $\mathrm{BMC}$ requires investigation.

CMAJ 2005;172(6):757-61 $\mathrm{n}$ northern countries, endogenous synthesis of vitamin $\mathrm{D}$ is thought to be limited to the months of April through September. ${ }^{1}$ During the winter months, dietary or supplemental vitamin D intake at values similar to the recommended intake of $200 \mathrm{IU} /$ day $(5 \mu \mathrm{g} / \mathrm{day})$ is not enough to prevent vitamin D deficiency in young women. ${ }^{2}$ Vitamin D deficiency is well documented among Canadian women $^{3-7}$ and young children ${ }^{4,8-11}$ and has been reported at levels as high as $76 \%$ of women and $43 \%$ of children (3-24 months) in northern Manitoba ${ }^{4}$ and $48.4 \%-88.6 \%$ of Aboriginal women and $15.1 \%-63.5 \%$ of non-Aboriginal women in the Inuvik zone of the former Northwest Territories. ${ }^{3}$ Vitamin D dependent rickets in children and osteomalacia in adults are the most commonly reported features of deficiency. ${ }^{12}$ We sought to determine whether maternal or infant vitamin D deficiency at birth is associated with $\mathrm{BMC}$ of Canadian infants.

\section{Methods}

The head obstetrics nurse screened all women admitted to the Winnipeg Health Sciences Centre (located at latitude $49.54^{\circ} \mathrm{N}$ ) for delivery of an infant during all weekdays (except holidays) until the desired sample size of 72 was achieved (August 2001 to April 2003). For entry to the study, an infant had to have an appropriate birth weight for gestational age as determined from US Centers for Disease Control and Prevention growth charts ${ }^{13}$ and weight greater than the third percentile ${ }^{13}$ and had to be free of congenital malformations. Mothers had to have undergone ultrasound dating to confirm gestational age of the infant, had to be healthy (as indicated by absence of gestational diabetes, hypertension and any long-term medical therapy) and had to be abstaining from use of nonmedicinal drugs such as cocaine, marijuana and alcohol. Women were entered into the study if they agreed to sampling of the infant's cord blood and follow-up dual-energy x-ray absorptiometry of the infant.

Cord blood and maternal blood (obtained within 48 hours of delivery) were collected into heparinized tubes, and plasma was separated from the red blood cells (by centrifugation at $2000 \times \mathrm{g}$ ) followed by storage at $-80^{\circ} \mathrm{C}$ until analysis. Vitamin D was measured as 25-hydroxyvitamin D [25(OH)D] in plasma using a radioimmunoassay (Diasorin, Stillwater, Minn.). The assay was run in accordance with the manufacturer's specifications, with a coefficient of variation of less than $10 \%$.

Infant weight and gestational age (based on ultrasound dating between 8 and 13 weeks) at birth were obtained from the medical record, as were maternal age at time of delivery, weight gain during pregnancy, height and use of prenatal vitamin and mineral supplements. Maternal prepregnancy weight was not consistently documented in the charts and thus was not used for analysis. 
At a follow-up visit (within 15 days of birth), the following infant dimensions were measured: weight to the nearest gram using an electric scale (model SB 32000, Mettler-Toledo Inc., Greifensee, Switzerland), length to the nearest $0.1 \mathrm{~cm}$ using an infant length board (O'Learly LengthBoards, Ellard Instrumentation Ltd., Seattle, Wash.) and head circumference to the nearest $0.1 \mathrm{~cm}$ using a nonstretchable tape (Perspective Enterprises, Portage, Mich.). The array mode of a dual-energy x-ray absorptiometer (QDR 4500A, Hologic Inc., Waltham, Mass.) was used to measure whole-body, lumbar spine (vertebrae 1-4) and wholefemur BMC. For the absorptiometry, each infant wore a single light sleeper with no metal or plastic components and a diaper and was wrapped in a single receiving blanket. BMC was expressed as absolute weight in grams and as grams per kilogram body weight (i.e., the body weight measured on the same day). At this visit, mothers were asked to self-identify their ethnicity from the following choices: white, First Nations, Asian, black, Filipino or other. They were also asked to provide a 24-hour recall of food intake, including supplement use. The 24-hour recall represented a weekday, and food models were used to help estimate portion sizes. In addition, 30 women also completed 3 -day (2 nonconsecutive weekdays plus 1 weekend day) written food records within the first 4 weeks after delivery. Records were checked for completeness, including portion sizes, cooking method and brand names. Where clarification was required, mothers were contacted by telephone. Vitamin D intake from food was estimated using a nutrient analysis program (Nutrient Analysis Program, E. Warwick, Long Creek, PEI) that includes the 1997 Canadian Nutrient File Database. The average total daily vitamin D intake for the 30 women completing both assessments was $200 \mathrm{IU} /$ day based on the 24-hour recalls and $248 \mathrm{IU} /$ day based on the 3-day record $(r=$ $0.76, p<0.001)$. As these results were strongly correlated, only the results for the 24-hour recall are reported for the full cohort.

\section{Table 1: Characteristics of mothers with deficient* or adequate vitamin $\mathrm{D}$ status}

\begin{tabular}{|c|c|c|c|}
\hline \multirow[b]{2}{*}{ Characteristic } & \multicolumn{2}{|c|}{ Vitamin D status; mean (SD)† } & \multirow[b]{2}{*}{$p$ value } \\
\hline & $\begin{array}{c}\text { Deficient } \\
n=23\end{array}$ & $\begin{array}{c}\text { Adequate } \\
n=27\end{array}$ & \\
\hline Race (white/nonwhite)§ & $8 / 15$ & $22 / 5$ & 0.002 \\
\hline Age, yr & $24.8(5.5)$ & $28.9(7.1)$ & 0.029 \\
\hline Height, cm & $162(8)$ & $161(7)$ & 0.64 \\
\hline $\begin{array}{l}\text { No. }(\%) \text { with education } \\
<\text { grade } 12\end{array}$ & $8(35)$ & $4(15)$ & 0.19 \\
\hline $\begin{array}{l}\text { Total weight gain in } \\
\text { pregnancy, } \mathrm{kg}\end{array}$ & $12.1(5.5)$ & $15.3(12.0)$ & 0.24 \\
\hline $\begin{array}{l}\text { No. }(\%) \text { delivering between } \\
\text { October and March }\end{array}$ & $14(61)$ & $9(33)$ & 0.10 \\
\hline $\begin{array}{l}\text { No. }(\%) \text { who took a maternal } \\
\text { supplement during pregnancy }\end{array}$ & $14(61)$ & $25(93)$ & 0.018 \\
\hline Vitamin D intake (IU/day) & $149(145)$ & $242(218)$ & 0.09 \\
\hline $\begin{array}{l}\text { No. }(\%) \text { delivering a vitamin D } \\
\text { deficient infant } \$\end{array}$ & $16(70)$ & $2(7)$ & $<0.001$ \\
\hline
\end{tabular}

Note: $\mathrm{SD}=$ standard deviation.

*Deficiency defined as plasma 25-hydroxyvitamin D [25(OH)D] less than $37.5 \mathrm{nmol} / \mathrm{L}$. †xcept where otherwise indicated.

$\ddagger$ Derived from $t$ tests for continuous data and chi-square tests for proportions or categorical data.

$\S$ Nonwhite comprises First Nations $(n=10)$, Asian $(n=5)$, Filipino $(n=3)$ and black $(n=2)$. $\uparrow$ Deficiency in infants defined as plasma $25(\mathrm{OH})$ D less than $27.5 \mathrm{nmol} / \mathrm{L}$.
The sample size was calculated on the basis of a sampling distribution of whole-body BMC that would vary from the population mean ${ }^{14}$ by $3 \mathrm{~g}$ with a standard deviation of $13 \mathrm{~g} .{ }^{15}$ The difference of $3 \mathrm{~g}$ was based on the error of $4 \%$ and an estimated population mean of $74 \mathrm{~g} ;{ }^{15}$ precision of measurement for infants is less than $2.3 \%{ }^{16}$ and differences between Hologic machines approximate $1.4 \%$ in children and adults. ${ }^{17}$ According to this calculation, the sample estimate was 51 infants, but we recruited 72 infants to allow for a potential attrition rate of $30 \%$.

The vitamin D status of mothers and infants was categorized as deficient or adequate, where deficiency was defined as plasma $25(\mathrm{OH}) \mathrm{D}$ concentration less than $37.5 \mathrm{nmol} / \mathrm{L}$ for mothers ${ }^{2}$ and less than $27.5 \mathrm{nmol} / \mathrm{L}$ for infants. ${ }^{2}$ Differences between deficient and adequate groups were tested using nonpaired $t$ tests for continuous data, and differences in proportions between groups were detected using a $\chi^{2}$ test for categorical data. The level of significance was set at a probability of 0.05 for all tests.

To determine if vitamin D status contributed to BMC outcomes, multiple linear regression models were constructed using backward stepwise regression analyses. The predictor variables included infant sex; maternal ethnicity; infant weight and gestational age at birth; infant weight, length, lean mass, postnatal and gestational age at time of follow-up; and maternal and infant vitamin $\mathrm{D}$ status.

The study protocol was reviewed and approved by the University of Manitoba Ethics Review Board.

\section{Results}

In total, 342 mothers who met the entry criteria permitted sampling of cord blood at the time of delivery, and 72 (21\%) consented to participate in the full study. The most common reasons for declining to participate were time constraints and maternal concerns about the use of $x$-ray absorptiometry to measure BMC. Of the 72 mother-infant pairs who agreed to participate, 22 were not included in the analysis because of dropping out $(n=11)$, lack of a maternal blood sample $(n=4)$ or late follow-up visit $(n=7)$. The results for 50 mother-infant pairs with a complete data set and studied within 15 days of delivery are reported here.

Plasma 25(OH)D was less than $37.5 \mathrm{nmol} / \mathrm{L}$ in 23 (46\%) of the 50 mothers, with an average of 28.6 (standard deviation $[\mathrm{SD}] 7.8) \mathrm{nmol} / \mathrm{L}$ in the deficient group and 61.6 (SD 24.7) $\mathrm{nmol} / \mathrm{L}$ in the adequate group. Maternal characteristics stratified by vitamin D status are reported in Table 1. A higher proportion of vitamin D deficient mothers had nonwhite ethnicity and delivered an infant with vitamin D deficiency. A lower proportion of deficient mothers took a maternal supplement. No other differences were observed between the maternal groups.

Eighteen $(36 \%)$ of the infants had plasma $25(\mathrm{OH}) \mathrm{D}$ less than $27.5 \mathrm{nmol} / \mathrm{L}$, with an average of $19.0(\mathrm{SD} 6.0) \mathrm{nmol} / \mathrm{L}$ in the deficient group and 39.7 (SD 10.6) $\mathrm{nmol} / \mathrm{L}$ in the adequate group. Infants deficient in vitamin D had higher birth weight as well as greater weight, length and head circumference at follow-up (Table 2), but lower whole-body and femur BMC relative to weight (Table 2). No other differences were observed between the infant groups. 
Whole-body BMC was predicted by a combination of 4 factors in the regression analysis. The final regression equation was $\mathrm{BMC}=-178.8+4.305$ (gestational age at birth [weeks] $)+0.021$ (birth weight $[\mathrm{g}])+0.332$ (infant vita$\min \mathrm{D}[\mathrm{nmol} / \mathrm{L}])-0.139$ (maternal vitamin $\mathrm{D}[\mathrm{nmol} / \mathrm{L}]) ; R$ $=0.859, p<0.001$ for gestational age and weight and $p<$ 0.028 for both vitamin $\mathrm{D}$ measurements. Thus, higher values for gestational age, birth weight and infant vitamin D status were associated with higher infant BMC, but (after accounting for infant vitamin D) maternal vitamin $D$ was negatively associated with BMC. Collinearity between infant and maternal vitamin $\mathrm{D}$ was not considered a contributing factor since these vitamin D concentrations were only correlated with each other at $r=0.67$. Infant sex, infant length and maternal ethnicity were not included in the final model since they did not significantly predict infant BMC.

\section{Interpretation}

Forty-six percent of healthy mothers and $36 \%$ of their infants were vitamin D deficient. Although all infants were of normal birth weight, as dictated by the entry criteria, those with vitamin $\mathrm{D}$ deficiency were on average heavier and longer than those with adequate vitamin D. Despite their greater size, these vitamin $\mathrm{D}$ deficient infants had lower whole-body BMC relative to body weight. This finding suggests that the vitamin $\mathrm{D}$ status observed among deficient infants in this study was unable to support adequate mineralization of bone. These heavier, longer infants were expected to have a higher $\mathrm{BMC}$ because their skeletons were larger; however, because of their vitamin $\mathrm{D}$ deficient state, they did not.

The findings that whole-body BMC is related to infant weight and gestational age but not to maternal ethnicity and infant sex have been reported by others. ${ }^{18,19}$ The present study adds to this knowledge the fact that after accounting for these variables, infant BMC is positively associated with infant vitamin D status. Therefore, larger infants will have greater BMC only if they have adequate vitamin $\mathrm{D}$. The inverse relation between infant $\mathrm{BMC}$ and maternal vitamin $\mathrm{D}$ concentration observed in the regression analysis, after accounting for infant gestational age, weight and vitamin D status at birth, is new and difficult to explain. Kamycheva and associates ${ }^{20}$ observed that women with higher vitamin $\mathrm{D}$ intake (> $112 \mathrm{IU} /$ day) were likely to have a healthy body mass index (BMI) of $24-25 \mathrm{~kg} / \mathrm{m}^{2}$. It is also known that women whose BMI is in this range in their first trimester have smaller infants (by $170 \mathrm{~g}$ ) than those with a higher BMI $\left(>25 \mathrm{~kg} / \mathrm{m}^{2}\right){ }^{21} \mathrm{In}$

\begin{tabular}{|c|c|c|c|}
\hline \multirow[b]{2}{*}{ Characteristic } & \multicolumn{2}{|c|}{ Vitamin D status; mean $(\mathrm{SD}) \dagger$} & \multirow[b]{2}{*}{$p$ value $\neq$} \\
\hline & $\begin{array}{l}\text { Deficient } \\
n=18\end{array}$ & $\begin{array}{c}\text { Adequate } \\
n=32\end{array}$ & \\
\hline \multicolumn{4}{|l|}{ Demographic } \\
\hline $\operatorname{Sex}(M / F)$ & $13 / 5$ & $16 / 16$ & 0.22 \\
\hline Race (white/nonwhite)§ & $6 / 12$ & $24 / 8$ & 0.010 \\
\hline $\begin{array}{l}\text { No. (and \%) born between October and } \\
\text { March }\end{array}$ & $11(611)$ & $13(41)$ & 0.27 \\
\hline \multicolumn{4}{|l|}{ At birth } \\
\hline Gestational age, wk & $39.5(0.8)$ & $39.6(0.9)$ & 0.70 \\
\hline Weight, g & $3698(380)$ & $3399(451)$ & 0.022 \\
\hline \multicolumn{4}{|l|}{ At time of DXA } \\
\hline Postnatal age, wk & $1.4(0.8)$ & $1.4(0.7)$ & $>0.99$ \\
\hline Weight, g & $3932(401)$ & $3511(414)$ & 0.001 \\
\hline Length, $\mathrm{cm}$ & $53.7(1.6)$ & $51.4(2.0)$ & $<0.001$ \\
\hline Head circumference, $\mathrm{cm}$ & $36.6(1.2)$ & $35.6(1.3)$ & 0.01 \\
\hline \multicolumn{4}{|l|}{ Bone and fat } \\
\hline Lumbar spine (1-4) BMC, g & $2.3(0.5)$ & $2.3(0.5)$ & $>0.99$ \\
\hline Lumbar spine (1-4) BMC/body weight, g/kg & $0.589(0.136)$ & $0.658(0.125)$ & 0.08 \\
\hline Femur BMC, g & $2.8(0.7)$ & $2.9(0.6)$ & 0.60 \\
\hline Femur BMC/body weight, g/kg & $0.706(0.174)$ & $0.813(0.146)$ & 0.027 \\
\hline Whole-body BMC, g & $76.4(12.9)$ & $75.7(13.7)$ & 0.86 \\
\hline Whole-body BMC/body weight, g/kg & $19.490(3.053)$ & $21.330(2.033)$ & 0.017 \\
\hline Whole-body fat, \% & $12.7(4.1)$ & $10.6(4.1)$ & 0.09 \\
\hline
\end{tabular}

Note: DXA = dual-energy $\mathrm{x}$-ray absorptiometry, $\mathrm{BMC}=$ bone mineral content.

*Deficiency defined as plasma 25(OH)D less than $37.5 \mathrm{nmol} / \mathrm{L}$.

†Except where otherwise indicated.

fDerived from $t$ tests for continuous data and $\chi^{2}$ tests for proportions or categorical data.

$\S$ Nonwhite comprises First Nations $(n=10)$, Asian $(n=5)$, Filipino $(n=3)$ and black $(n=2)$. 
addition, mothers randomly assigned to receive a bolus dose of vitamin D (200000 IU) to correct deficiency at the seventh month of gestation delivered infants $250 \mathrm{~g}$ lighter than the control group. ${ }^{22}$ The possibility that behaviours related to maternal body weight and vitamin D status interact to regulate infant body weight requires further investigation.

This study was limited by the small sample size. In addition, our study population had a higher proportion $(n=10$ [20\%]) of First Nations people than the Winnipeg population in $2001(8.4 \%){ }^{23}$ This difference may be explained by the higher birth rate for this group (23.0 births per 1000 people within the First Nations population v. 11.1 births per 1000 people in the Canadian population), as well as its younger age. ${ }^{24}$ There are no data on BMC of First Nations infants to indicate if this high proportion affected our results. Nonetheless, the values we obtained for whole-body $\mathrm{BMC}$ were similar to other Canadian data, ${ }^{15}$ and the values for maternal vitamin $\mathrm{D}$ intake and status were similar to data presented in other Canadian reports. ${ }^{6,7}$

The cause of persistent vitamin D deficiency among women $^{25-30}$ and infants ${ }^{26-32}$ throughout the world is not entirely clear. Vitamin D deficiency persists despite consumption by some women of more than 200 IU of vitamin D per day, as documented in our study and by others. ${ }^{6}$ In Canada, vitamin D fortification of commercially available cow's milk and margarine for the primary prevention of vitamin $\mathrm{D}$ deficiency was thought to be effective. ${ }^{33}$ While dietary assessment is difficult and might not reflect true intake, our data suggest that the dietary requirements for pregnant women in Canada and the United States should be higher than the currently recommended levels of at least $200 \mathrm{IU} / \mathrm{day}^{2}{ }^{2}$ The recommendation of $900 \mathrm{IU}$ vitamin D per day for Aboriginal women who are pregnant ${ }^{34}$ might be more appropriate in northern Canada and other areas where exposure to sunshine is limited. Canadian recommendations for healthy term infants suggest that, in communities where deficiency is prevalent, infants should receive $800 \mathrm{IU}$ of vitamin D daily. ${ }^{35}$ A comprehensive assessment of vitamin D status among Canadians, through documentation of dietary intake from foods and supplements and assessment of endogenous synthesis, is required to guide fortification and supplementation policies for Canadians.

Although the perils of overt vitamin D deficiency are known, the effects of mild to moderate vitamin $\mathrm{D}$ deficiency and lowered $\mathrm{BMC}$ at birth remain to be seen. Although there are no reports of an association between BMC and vitamin D status at birth and subsequent development of osteoporosis, a growing body of literature links suboptimal intrauterine environment with later bone mass of the hip. ${ }^{36}$ Whether correction of vitamin D deficiency after birth will prevent subsequent negative outcomes related to bone health is unknown. The vitamin $\mathrm{D}$ status of pregnant women and infants should be optimized to achieve bone health that will last a lifetime.
This article has been peer reviewed.

From the Departments of Human Nutritional Sciences (Weiler, FitzpatrickWong, Veitch, Kovacs, Schellenberg, McCloy), of Pediatrics and Child Health (Weiler) and of Obstetrics and Gynecology (Yuen), University of Manitoba, Winnipeg, Man.

Competing interests: None declared.

Contributors: The study was conceived and the manuscript written by Hope Weiler. Shirley Fitzpatrick-Wong was responsible for the majority of the vitamin D analyses. Jeannine Schellenberg, Ursula McCloy, Rebecca Veitch and Heather Kovacs were responsible for recruitment, sample collection and follow-up measurements. Chui Kin Yuen participated in the development of the study and advised on recruitment methodology. All authors contributed to critical evaluation of the manuscript and gave final approval for the article to be published.

Acknowledgements: This research was supported by grants from the Manitoba Health Research Council and the Canadian Institutes of Health Research. The densitometer used in the study was purchased and maintained by the Manitoba Institute of Child Health. Ursula McCloy received a postdoctoral fellowship and Heather Kovacs received a graduate scholarship from the Manitoba Institute of Child Health. Hope Weiler is in receipt of a New Investigator Salary Award from the Canadian Institutes of Health Research.

\section{References}

1. Webb AR, Kline L, Holick MF. Influence of season and latitude on the cutaneous synthesis of vitamin D3: exposure to winter sunlight in Boston and Edmonton will not promote vitamin D3 synthesis in human skin. 7 Clin Endocrinol Metab 1988;67:373-8.

2. Institute of Medicine. Dietary reference intakes for calcium, phosphorus, magnesium, vitamin D, and fluoride. Washington: National Academy Press; 1997.

3. Waiters B, Godel JC, Basu TK. Perinatal vitamin D and calcium status of northern Canadian mothers and their newborn infants. 7 Am Coll Nutr 1999; 18:122-6.

4. Lebrun JB, Moffatt ME, Mundy RJ, Sangster RK, Postl BD, Dooley JP, et al. Vitamin D deficiency in a Manitoba community. Can 7 Public Health 1993;84: 394-6.

5. Gibson RS, Bindra GS, Nizan P, Draper HH. The vitamin D status of East Indian Punjabi immigrants to Canada. Br 7 Nutr 1987;58:23-9.

6. Vieth R, Cole DE, Hawker GA, Trang HM, Rubin LA. Wintertime vitamin $\mathrm{D}$ insufficiency is common in young Canadian women, and their vitamin D intake does not prevent it. Eur 7 Clin Nutr 2001;55:1091-7.

7. Rucker D, Allan JA, Fick GH, Hanley DA. Vitamin D insufficiency in a population of healthy western Canadians. CMAf 2002;166(12):1517-24

8. Dilling LA, Ellestad-Sayed J, Coodin FJ, Haworth JC. Growth and nutrition of preschool Indian children in Manitoba: I. Vitamin D deficiency. Can 7 Public Health 1978;69:248-52.

9. Haworth JC, Dilling LA. Vitamin-D-deficient rickets in Manitoba, 1972-84. CMA7 1986;134(3):237-41.

10. Binet A, Kooh SW. Persistence of vitamin D-deficiency rickets in Toronto in the 1990s. Can 7 Public Health 1996;87:227-30.

11. Innes A, Seshia M, Prasad C, Saif S, Friesen F, Chudley A, et al. Congenital rickets caused by maternal vitamin D deficiency. Paediatr Child Health 2002;7: 455-8.

12. Holick MF. Vitamin D: a millennium perspective. 7 Cell Biochem 2003;88: 296-307.

13. Clinical growth charts. National Center for Health Statistics. Atlanta: Centers for Disease Control and Prevention; 2000. Available: www.cdc.gov/nchs/about /major/nhanes/growthcharts/clinical_charts.htm (accessed 2005 Jan 31).

14. Colton T. Statistics in medicine. 1st ed. Boston: Little, Brown and Company; 1974

15. Atkinson SA, Randall-Simpson J. Factors influencing body composition of premature infants at term-adjusted age. Ann N Y Acad Sci 2000;904:393-9.

16. Brunton JA, Weiler HA, Atkinson SA. Improvement in the accuracy of dual energy $\mathrm{x}$-ray absorptiometry for whole body and regional analysis of body composition: validation using piglets and methodologic considerations in infants. Pediatr Res 1997;41:590-6.

17. Ellis KJ, Shypailo RJ. Bone mineral and body composition measurements: cross-calibration of pencil-beam and fan-beam dual-energy X-ray absorptiometers. 7 Bone Miner Res 1998;13:1613-8.

18. Namgung R, Tsang RC. Factors affecting newborn bone mineral content: in utero effects on newborn bone mineralization. Proc Nutr Soc 2000;59:55-63.

19. Koo WW, Walters J, Bush AJ, Chesney RW, Carlson SE. Dual-energy X-ray absorptiometry studies of bone mineral status in newborn infants. $\mathcal{F}$ Bone Miner Res 1996;11:997-1102.

20. Kamycheva E, Joakimsen RM, Jorde R.Intakes of calcium and vitamin D predict body mass index in the population of northern Norway. 7 Nutr 2003;133:102-6.

21. Shapiro C, Sutija VG, Bush J. Effect of maternal weight gain on infant birth weight. 7 Perinat Med 2000;28:428-31. 
22. Mallet E, Gugi B, Brunelle P, Henocq A, Basuyau JP, Lemeur H. Vitamin D supplementation in pregnancy: a controlled trial of two methods. Obstet Gynecol 1986;68:300-4.

23. Population reporting Aboriginal identity in selected census metropolitan areas with an Aboriginal population of 5000 or more, 1996 and 2001. Ottawa: Statistics Canada; 2001.

24. First Nations and Inuit Health Branch. Statistical profile on the bealth of First Nations in Canada. Ottawa: Health Canada, Health Information and Analysis Division; 2003. Document AL\#1921D.

25. Weisman Y. Maternal, fetal and neonatal vitamin D and calcium metabolism during pregnancy and lactation. Endocr Dev 2003;6:34-49.

26. Goswami R, Gupta N, Goswami D, Marwaha RK, Tandon N, Kochupillai N. Prevalence and significance of low 25-hydroxyvitamin D concentrations in healthy subjects in Delhi. Am 7 Clin Nutr 2000;72:472-5.

27. Dawodu A, Agarwal M, Hossain M, Kochiyil J, Zayed R. Hypovitaminosis D and vitamin D deficiency in exclusively breast-feeding infants and their mothers in summer: a justification for vitamin $\mathrm{D}$ supplementation of breast-feeding infants. F Pediatr 2003;142:169-73

28. Bassir M, Laborie S, Lapillonne A, Claris O, Chappuis MC, Salle BL. Vitamin D deficiency in Iranian mothers and their neonates: a pilot study. Acta Paediatr 2001;90:577-9.

29. Andiran N, Yordam N, Ozon A. Risk factors for vitamin D deficiency in breast-fed newborns and their mothers. Nutrition 2002;18:47-50.
30. Nozza JM, Rodda CP. Vitamin D deficiency in mothers of infants with rickets. Med 7 Aust 2001;175:253-5.

31. Johnson GH, Willis F. Seizures as the presenting feature of rickets in an infant. Med F Aust 2003;178:467, discussion 467-8.

32. Pedersen P, Michaelsen KF, Molgaard C. Children with nutritional rickets referred to hospitals in Copenhagen during a 10-year period. Acta Paediatr 2003;92:87-90.

33. Addition of vitamins and minerals to foods. Proposed policy recommendations. Ottawa: Health Canada, Bureau of Nutritional Sciences, Food Directorate, Health Protection Branch; 1999.

34. Canadian Paediatric Society. Vitamin D supplementation in northern Native communities. Paediatr Child Health 2002;7:459-465.

35. Nutrition for healthy term infants. Statement of the foint Working Group: Canadian Paediatric Society, Dietitians of Canada, Health Canada. Ottawa: Health Canada; 1998.

36. Cooper C, Javaid MK, Taylor P, Walker-Bone K, Dennison E, Arden N. The fetal origins of osteoporotic fracture. Calcif Tissue Int 2002;70:391-4.

Correspondence to: Dr. Hope Weiler, H513 Duff Roblin,

University of Manitoba, 190 Dysart Rd., Winnipeg MB R3T 2N2;

fax 204 474-7593; hweiler@cc.umanitoba.ca

\section{Writing for CMAJ}

CMAJ publishes papers that advance the understanding of medicine and health care, stimulate debate, educate and entertain. Most submissions arrive unsolicited, and we welcome them. Contributors should consult the instructions for authors on eCMAJ (www.cmaj.ca/misc/ifora.shtml).

Research articles report original findings of interest to a general medical audience. Articles should be no more than 2500 words long. Novel case reports will also be considered for the Research section. Research letters are short (500 words) reports that do not require extensive elaboration with respect to methods and results.

Although most Commentaries are written at our invitation, we welcome unsolicited submissions and suggestions for topics and contributors. Commentaries require a succinct and confident style, a clear point of view and a degree of balance.

The Review section contains comprehensive, peerreviewed summaries of recent advances in basic science or clinical practice (systematic and narrative reviews). Most submissions should be no longer than 2000 words.

Practice contains brief articles (1000-1200 words) that present or review information for physicians in practice. It includes case reports and short papers that do not qualify as original research but remind physicians of important clinical situations. Prospective authors should contact the editors to discuss ideas and projects.
The Left Atrium gives readers room for reflection. Book and film reviews are solicited by the editor. We welcome unsolicited poetry, fiction and creative nonfiction. The writing should be candid, but patient confidentiality must be respected. If you would like to be added to our list of book reviewers or to discuss ideas for contributions, please contact the senior deputy editor, Anne Marie Todkill.

Letters to the Editor commenting on published articles or of general interest are welcome. Brevity is highly prized: submissions should be no more than 250 words long and appropriately referenced. The most effective letters usually raise a single, tersely argued point. Authors whose work is discussed are given an opportunity to respond.

For the unabridged version of Writing for $C M A J$, see our Web site at cmaj.ca

Editor, CMAJ

John Hoey, MD

$800663-7336 \times 2118$

john.hoey@cma.ca

To contact other CM AJ staff members, please consult the masthead at the front of the journal or send an email message to pubs@cma.ca 